\title{
Surgical considerations in regard to Denonvilliers' fascia
}

\author{
NOBUKI FURUBAYASHI ${ }^{1}$, MOTONOBU NAKAMURA ${ }^{1}$, YOSHIFUMI HORI ${ }^{1}$, \\ KEN HISHIKAWA $^{1}$, KEN-ITI NISHIYAMA ${ }^{2}$ and YOSHIHIRO HASEGAWA ${ }^{1}$ \\ Departments of ${ }^{1}$ Urology, and ${ }^{2}$ Pathology, National Kyushu Cancer Center, Fukuoka 811-1395, Japan
}

Received September 14, 2009; Accepted December 11, 2009

DOI: 10.3892/ol_00000069

\begin{abstract}
In this study, the region between the prostate and the rectum was examined. We reviewed, macroscopically, the clinical anatomy of the perioperative regions and excised specimens. Moreover, using fixed specimens from three cases of total pelvic exenteration, we histologically reviewed the regions between the prostate and rectum. Following bladder neck transection, the deferent duct was observed in connective tissues that continued to Denonvilliers' fascia. When the prostate was pulled ventrally, this connective tissue was identified as a sheet of membrane that traversed from the anterior prostate to the dorsal rectum. The dorsal surface of the specimen appeared to be covered with a thin membrane, and the regions that continued from this thin membrane were judged macroscopically as a stump. Between the prostate and the rectum, intricate connective tissue was present in the fixed specimen that was removed via a total pelvic exenteration. This connective tissue continued to the connective tissue surrounding the seminal vesicles and prostate. The complex connective tissue was present anatomically between the prostate and rectum. As a result of the surgical procedures, this connective tissue was identified surgically as Denonvilliers' fascia.
\end{abstract}

\section{Introduction}

In 1836 , the membranous structure between the rectum and the seminal vesicles was named Denonvilliers' fascia after Charles-Pierre Denonvilliers (1). Denonvilliers' fascia has been a surgical landmark that urologists must consider during intrapelvic surgery $(2,3)$. Denonvilliers' fascia consists of a single layer arising from the fusion of the two walls of the embryological peritoneal cul-de-sac, under embryological and anatomical review (4). In our institution, a urologic intrapelvic surgery was performed, utilizing Denonvilliers' fascia. However, experienced urologists should not disregard cases where Denonvilliers' fascia is identified in surgery, and cases where Denonvilliers' fascia is not noted in radical

Correspondence to: Dr Nobuki Furubayashi, Department of Urology, National Kyushu Cancer Center, Notame 3-1-1, Minami-ku, Fukuoka 811-1395, Japan

E-mail: furubayashi.n@nk-cc.go.jp

Key words: Denonvilliers' fascia, connective tissues, prostate, rectum prostatectomy. The incidence of such differences is frequent. To assess these differences, we reviewed the intraoperative findings and the excised specimens obtained during a radical prostatectomy, as well as fixed specimens obtained during total pelvic exenteration.

\section{Materials and methods}

Between April 2008 and March 2009, at our institution, the clinical anatomy of perioperative regions and excised specimens were reviewed macroscopically for 62 cases of antegrade radical prostatectomy. Not all cases had a treatment history for prostate cancer preoperatively. We observed the relationship between the deferent duct and the surrounding tissue after bladder neck transection, macroscopically. We also observed the detachment between the prostate and rectum, following deferential ligation and ablation, as well as the seminal vesicle detachment, macroscopically. In addition, we observed the dorsal surface of the excised specimen macroscopically. Finally, we histologically examined the region between the prostate and rectum using fixed specimens from three cases that underwent total pelvic exenteration performed during the same time period.

\section{Results}

Observed relationship between the deferent duct, following bladder neck transection, and the surrounding tissue, macroscopically. Observations were dorsal in nature after bladder neck transection. The deferent duct was observed in the connective tissue (Fig. 1). When the surgeon grasped a deferent duct, he was able to confirm that an intricate connective tissue clung to the surrounding region (Fig. 2). In addition, it was confirmed that this connective tissue continued to Denonvilliers' fascia from the dorsum to the area where the deferent duct was ligated and separated (Fig. 3).

Observed detachment between the prostate and rectum, following deferential ligation/ablation and seminal vesicle detachment macroscopically. When the prostate was pulled ventrally, Denonvilliers' fascia was observed. It extended from the anterior prostate to the dorsal rectum, and was present in the form of a sheet of membrane (Fig. 4). This membrane did not differ from that which continued to Denonvilliers' fascia (Fig. 3). A membrane was observed when the prostate was pulled more ventrally and the bladder was pulled more 


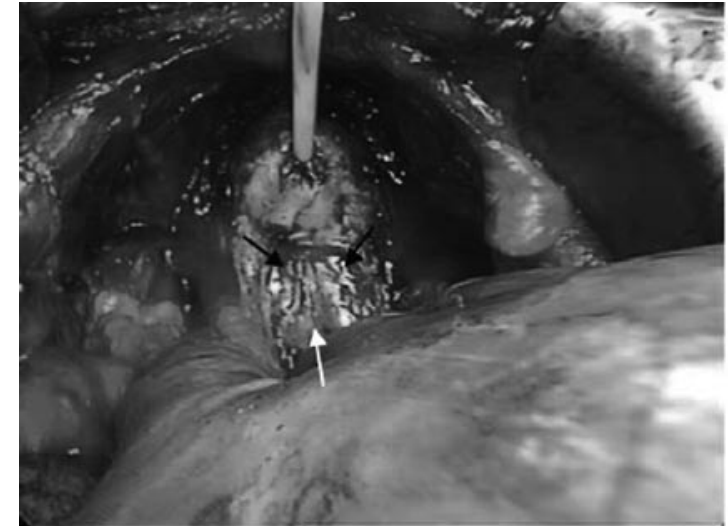

Figure 1. The deferent duct (black arrows) was observed in connective tissue (white arrow) after bladder neck transection.

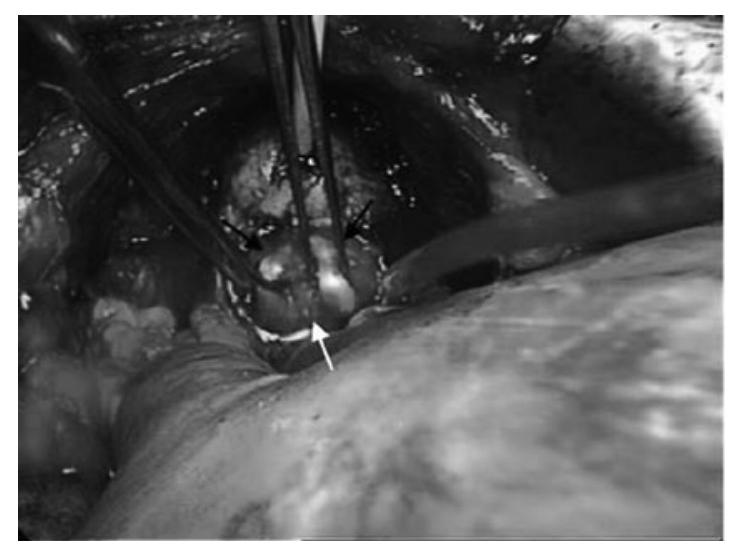

Figure 2. After grasping the deferent duct (black arrows), the presence of intricate connective tissue (white arrow) that clung to the surrounding region of the deferent duct was confirmed.

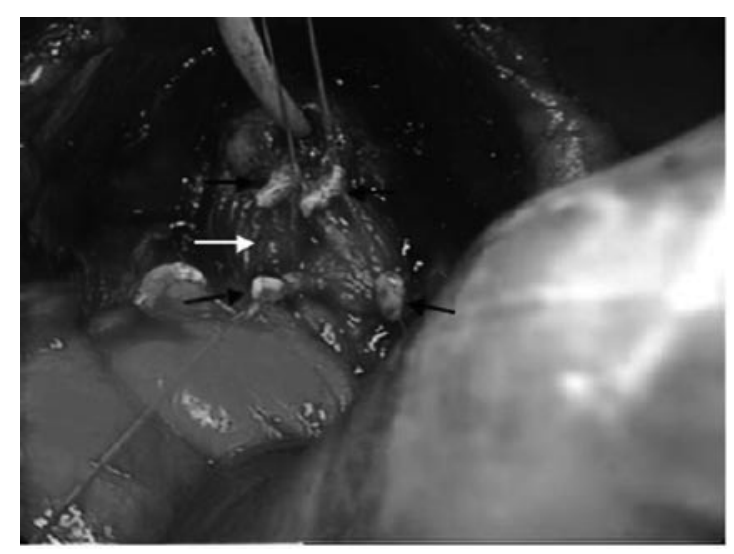

Figure 3. The connective tissue (white arrow) present in the dorsum of the deferent duct (black arrows) continued to Denonvilliers' fascia in the area where the bilateral deferent duct was ligated and separated.

dorsally. The webbed connective tissue was observed more distally when the membranous structure was sharply cut open (Fig. 5). In addition, the webbed connective tissue was identified as a new membranous structure when tension was applied to the tissue. A series of repeated operations was possible as stated above.

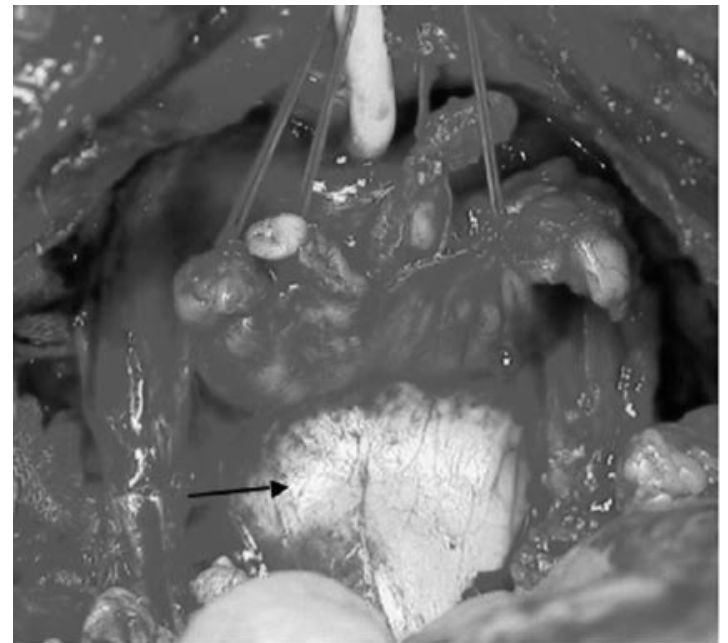

Figure 4 . When the prostate was pulled more ventrally, a membranous structure was recognized between the prostate and the rectum, and this structure is Denonvilliers' fascia (black arrow).

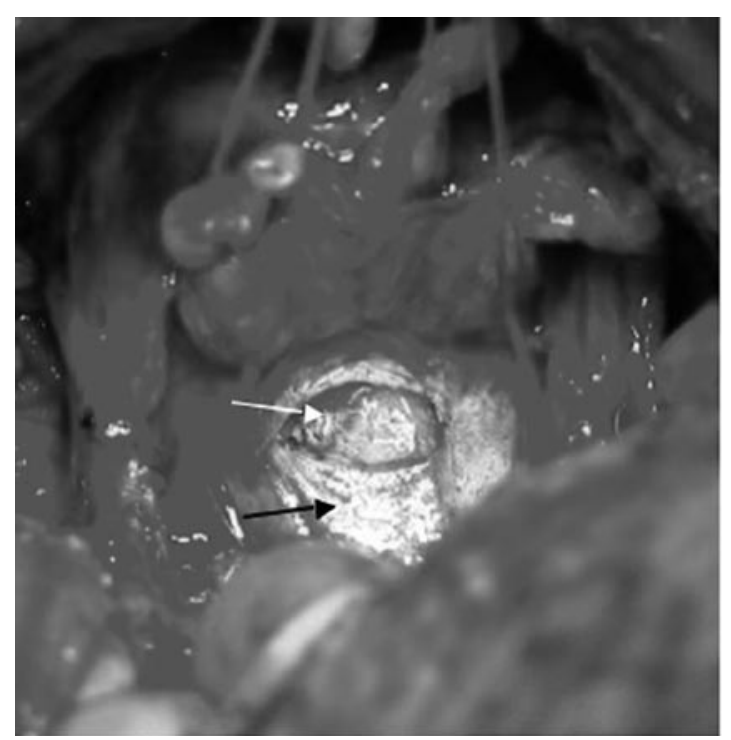

Figure 5. After cutting, Denonvilliers' fascia (black arrow) opened sharply. The webbed connective tissue (white arrow) was observed more distally from the dissected Denonvilliers' fascia.

Dorsal macroscopic observation in the prostatectomy specimen. The dorsal side of the specimen appeared to be covered by the thin membrane. Furthermore, several regions that continued along this thin membrane were noted. These regions appeared macroscopically as a stump (Fig. 6).

Histological examination of the fixed specimen removed in the total pelvic exenteration. Intricate connective tissue and fat were present between the prostate and rectum in the 62 cases. These tissues continued to the connective tissue around the seminal vesicles and prostate (Fig. 7).

\section{Discussion}

Although Denonvilliers' fascia is present between the prostate and rectum anatomically, Denonvilliers' fascia cannot be 


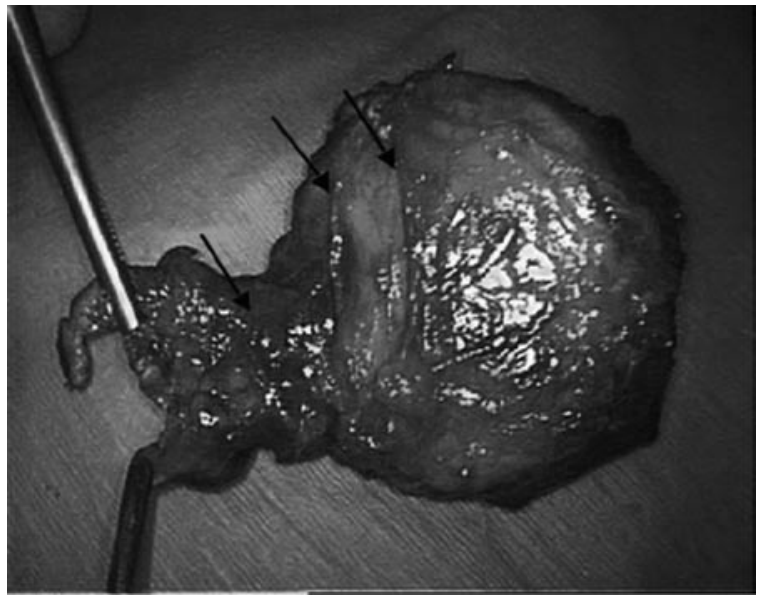

Figure 6. The dorsal aspect of the specimen appeared to be covered with a thin membrane. Furthermore, three parts continued along this thin membrane and were judged, macroscopically, to be a stump (thick arrows). These stumps (Fig. 10; arrowhead) were created after Denonvilliers' fascia was cut open and the tension was mitigated in order to remove the prostate.

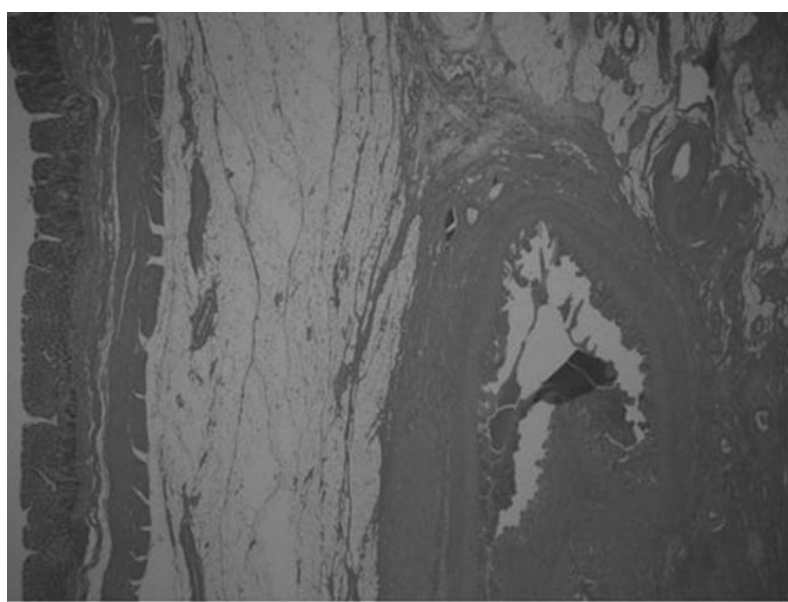

Figure 7. The fixed specimen obtained from the total pelvic exenteration The presence of fat and the connective tissue are observed at several levels between the prostate and rectum. These connective tissues continued to join those around the seminal vesicles and prostate.

identified in all surgical cases. Urologic surgeons may accomplish surgery more securely and safely when they can identify Denonvilliers' fascia without becoming perplexed by the differences present in each sugical case.

We firstly observed Denonvilliers' fascia during a an antegrade radical prostatectomy, macroscopically. To solve such contradictions, five findings were focused on. It was noted that i) a connective tissue clung to the deferent duct following bladder neck transection and that the connective tissues were separated from the deferent duct; ii) the connective tissues that clung to the deferent duct continued to Denonvilliers' fascia; iii) Denonvilliers' fascia was identified as a membranous structure surgically; iv) the webbed connective tissue was observed more distally when the membranous structure was sharply cut open and v) the webbed connective tissue was identified as a membranous structure again as tension was applied to this webbed connective tissue.

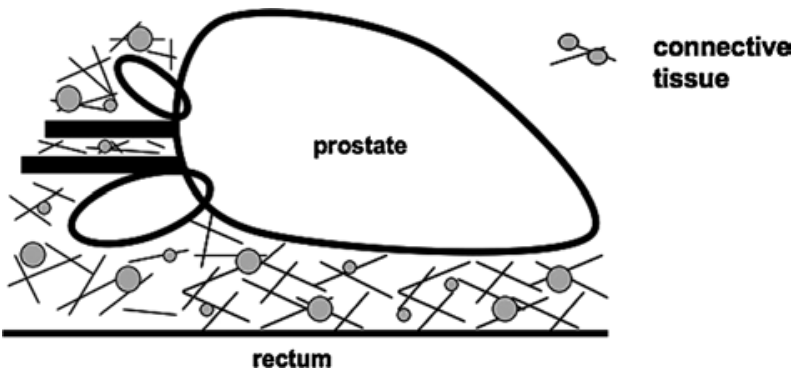

Figure 8 . The presence of intricate connective tissue was observed between the prostate and rectum. This connective tissue joins with that surrounding the deferent duct and seminal vesicles.

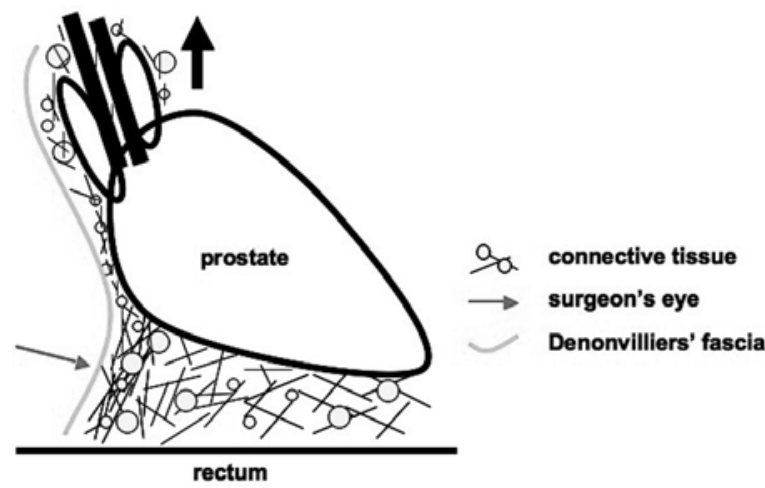

Figure 9. Tension was applied to the intricate connective tissue by pulling the seminal vesicles, deferent duct and prostate ventrally (thick arrow). This connective tissue then changed to a membranous structure identified as Denonvilliers' fascia (thin arrow).

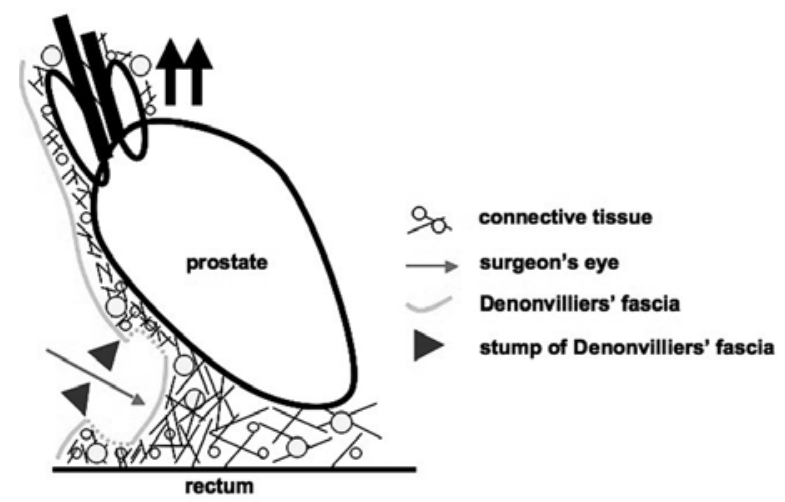

Figure 10. The condition resulting from the incision of Denonvilliers' fascia. While tension was applied, an incision was made into the tissue. As a result Denonvilliers' fascia (Fig. 6) showed a reduction in tension (arrowheads). In addition, the prostate was pulled more ventrally (thick arrow) and tension was applied to the connective tissue, which was observed more distally. Consequently, the connective tissue was identified as a new membranous structure (thin arrow).

As a result of these findings, we believe that Denonvilliers' fascia may be perceived surgically only as an intricate connective tissue. In other words, the intricate connective tissue present in three dimensions gave the appearance of a membranous structure in two dimensions since tension was 
applied to this connective tissue in a definite direction, and this new membranous structure was recognized merely as a membrane surgically.

We represented this structure schematically to fully explain the misleading two-dimensional appearance of this connective tissue. As a result of these findings, we conclude that the connective tissue between the prostate and rectum is complex. Moreover, this connective tissue continues with the connective tissue around the deferent duct and seminal vesicles (Fig. 8). As the seminal vesicles, deferent duct and prostate are pulled ventrally to develop an operative field, tension can be applied to this connective tissue. This connective tissue changes to a membranous structure and may be identified as Denonvilliers' fascia (Fig. 9). While tension was applied to the tissue, an incision was made to Denonvilliers' fascia, and this membranous structure mitigated the tension (arrowheads). In addition, the prostate was pulled more ventrally and tension was applied to the connective tissue which was noted more distally. Consequently, the connective tissue was identified as a new membranous structure. Thus, the above-mentioned series of operations may lead to the identification of the membranous structure, Denonvilliers' fascia. This identification occurred while tension was applied to the connective tissue when it was in a state of no tension due to previous perioperative operations (Fig. 10).

When we observed macroscopically the dorsum of a specimen from a radical prostatectomy, the dorsal surface of the prostate appeared to be covered with a thin membrane that we considered to be Denonvilliers' fascia. It was noted in several parts of the area which continued with Denonvilliers' fascia, but which were judged macroscopically to be a stump (Fig. 6). This stump which continued along Denonvilliers' fascia was different in number. The stump also varied with respect to the region and the thickness in each prostatectomy specimen. Denonvilliers' fascia, which changed shape from a connective tissue to a membranous structure upon the application of tension, released tension upon perioperative operation. Therefore, the issue that arises is whether the stumps of Denonvilliers' fascia, which represent a congregation of connective tissue, is present in various forms in different specimens.

Finally, we examined three cases of fixed specimens between the prostate and rectum in the pelvic exenteration.
We noted that the fat and connective tissue were present intricately at several levels between the prostate and rectum in the 62 cases. These fixed specimens of the pelvic exenteration cases are thought to be in an approximate state to the living body (Fig. 7). It was thought that these results also supported our observations of Denonvilliers' fascia.

Therefore, the reason for the surgical understanding of the Denonvilliers' fascia differing in each case may be that the quantity of connective tissue identified as Denonvilliers' fascia is dissimilar and that its tension varies. It is beneficial that a surgeon performing urological intrapelvic surgery understand that Denonvilliers' fascia is identified surgically as a structure consisting of connective tissue by a detachment operation. In addition, the fascia itself consists of a complex dense connective tissue. Moreover, it can be speculated that retroperitoneal fascia is similar to Denonvilliers' fascia in its constitution. We consistently discussed the membranous structure in the surgical procedure, but we did not discuss the structure either embryologically or anatomically.

In conclusion, intricate connective tissue was anatomically present between the prostate and the rectum. A surgeon separated and applied tension to this connective tissue and in the process created a membranous structure. This structure was surgically identified as Denonvilliers' fascia.

\section{Acknowledgements}

The authors thank Mr. Brian Quinn for the linguistic comments and help with the manuscript.

\section{References}

1. Denonvilliers CPD: Anatomie du perinee. Bull Soc Anat 11: 105, 1836.

2. Young HH: The early diagnosis and radical cure of carcinoma of the prostate. Being a study of 40 cases and a presentation of a radical operation, which was carried out in 4 cases. Johns Hopkins Hosp Bull 16: 315, 1905.

3. Young HH: The cure of cancer of the prostate by radical perineal prostatectomy (prostato-seminal vesiculectomy): history, literature and statistics of Young's operation. J Urol 143: 1166, 1990.

4. Van Ophoven A and Roth S: The anatomy and embryological origins of the fascia of Denonvilliers: a medico-historical debate. J Urol 157: 3-9, 1997. 